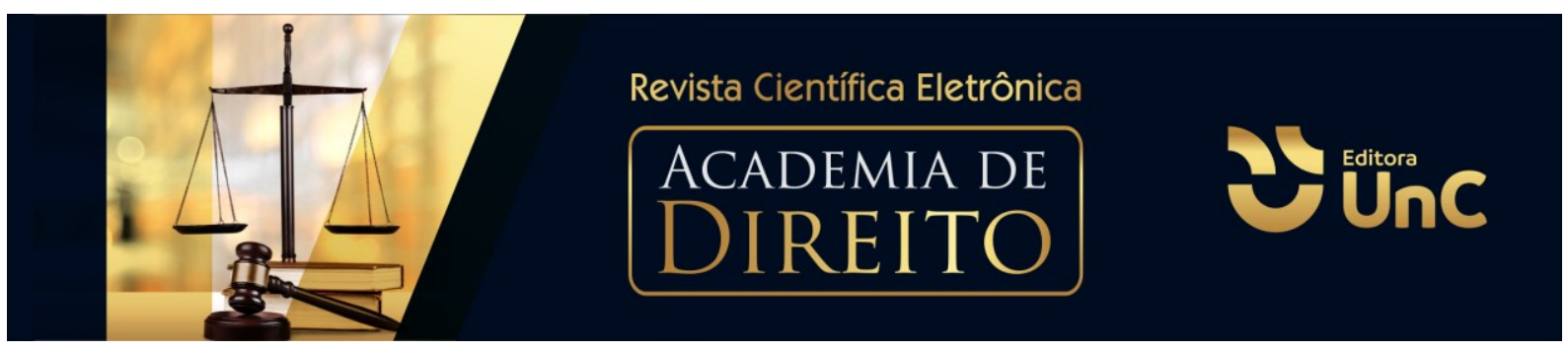

\title{
GUARDA COMPARTILHADA COMO GARANTIA DO PRINCÍPIO DO MELHOR INTERESSE DA CRIANÇA E DO ADOLESCENTE
}

\section{SHARED GUARD AS A GUARANTEE OF THE PRINCIPLE OF THE BEST INTEREST OF CHILDREN AND ADOLESCENTS}

\author{
Andreia Sperkoski ${ }^{1}$ \\ Adriane de Oliveira Ningeliski²
}

\begin{abstract}
RESUMO
Com o presente artigo se pretende analisar a guarda compartilhada como garantia do princípio do melhor interesse da criança e do adolescente. Tem como objetivo descrever a família na atualidade, conceituando e identificando os novos arranjos familiares, identificar os tipos de guarda no direito brasileiro e sua relação com o poder familiar e, por fim, verificar se a utilização da guarda compartilhada atenderia o princípio do melhor interesse da criança e do adolescente. O método adotado para o artigo decorre de uma ampla revisão bibliográfica em doutrinas e artigos científicos de revistas renomadas, sendo o método de abordagem o dedutivo, tendo em vista que se parte da premissa que a guarda compartilhada garantiria o melhor interesse da criança e do adolescente. Pode-se concluir que o instituto da guarda compartilhada, atualmente, é o mais adotado dentro dos tribunais e também mais indicado pelo Superior Tribunal de Justiça, bem como é regra do Código Civil, pois é o que melhor atende os anseios da criança e do adolescente, fazendo com que os laços afetivos com ambos os pais permaneçam durante seu desenvolvimento.
\end{abstract}

Palavras-Chave: Guarda Compartilhada. Melhor Interesse. Criança. Adolescente.

\section{ABSTRACT}

With the article, it is possible to analyze shared custody as a guarantee of the principle of the best interest of children and adolescents. It aims to describe a family today, to conceive and identify new family arrangements, to identify the types of custody in Brazilian law and its relationship with family power and, finally, to verify whether the use of shared custody is allowed or the best interest of children and adolescents. The method adopted for the article of a comprehensive bibliographic review on doctrines and scientific articles from renowned journals, and has three chapters on an approach to the theme. You can conclude whether the shared

\footnotetext{
${ }^{1}$ Acadêmica do Curso de Direito da Universidade do Contestado (UnC). Campus Mafra. Santa Catarina. Brasil. E-mail: andreia.sperkoski@aluno.unc.br

2Doutoranda e Mestre em Direito, Centro Universitário Autônomo do Brasil, Docente e Pesquisadora da Universidade do Contestado. Santa Catarina. Brasil. E-mail: adriane@unc.br
} 
custody institute is currently the most adopted within the courts and also more indicated by the Superior Court of Justice, as it is the best to serve adolescents and adolescents, making those affected with both parents remain for its development.

Keywords: Guard. Shared. Best. Interest.

\section{INTRODUÇÃO}

O instituto da guarda é um mecanismo que existe para prover a segurança e o bem estar dos filhos menores de idade, isto é, daqueles que não podem prover por si mesmos e devem, por força da lei, serem tutelados por seus responsáveis até seu ingresso a vida adulta. O vocábulo guarda e todas as suas flexões e múltiplas compreensões são todos compreendidos por este instrumento jurídico. Com o passar dos anos e as modificações estabelecidas pela sociedade, novos modos de se estabelecer a guarda se fizeram necessários e se provaram mais benéficos a criação do infante, surgindo então a guarda compartilhada.

O método abordado para a elaboração do artigo decorre de uma ampla revisão bibliográfica em doutrinas voltadas ao Direito de Família e ao Estatuto da Criança e do Adolescente, sendo ele dedutivo.

A presente pesquisa demonstra a importância da guarda compartilhada atualmente como melhor interesse para a criança e o adolescente, visto que com os diversos casos de divórcios, é necessário encontrar alternativas para manter o convívio e relação entre os pais e os filhos, bem como manter viva a relação entre todos e atender todos os interesses que os filhos precisar para ter contato com ambos os pais. Desta forma, questiona-se, a utilização da guarda compartilhada, no direito civil brasileiro, atenderia o melhor interesse da criança e do adolescente?

O primeiro capítulo visa descrever a família na atualidade, conceituando e identificando os novos arranjos familiares.

O segundo capítulo tem como objetivo identificar os tipos de guarda no direito brasileiro e sua relação com o poder familiar.

E, por fim, no terceiro capítulo busca-se verificar se a utilização da guarda compartilhada atenderia o princípio do melhor interesse da criança e do adolescente. 


\section{A FAMÍLIA}

A palavra "família" deriva do latim família, que se origina de famulus, designando o servidor, o criado. A família podia ser entendida como o locus onde reinava o pater, abrigando, em seu âmago, além deste, a esposa, os filhos, o patrimônio, os criados e os servos (NADAUD apud, MALUF; MALUF, 2016, p. 25).

Para Rolf Madaleno (2020, p. 1), tendo como marco inicial a Carta Federal de 1988, o Direito de Família passou a ser balizado pela ótica exclusiva dos valores maiores da dignidade e da realização da pessoa humana, sem desconsiderar os notáveis avanços da ciência, permitindo a pesquisa certeira da identidade genética para investigação da paternidade ou da maternidade.

Desta forma, importante se faz conceituar o instituto da família, bem como sua origem.

\subsection{CONCEITO}

Segundo Pereira (2020, p. 20), em sentido genérico e biológico, considera-se família o conjunto de pessoas que descendem de tronco ancestral comum.

A família pode ser reconhecida como:

A célula mater da sociedade, a família é fundamental para a sobrevivência da espécie humana. É a referência existencial do ser humano, caracterizando-se pela união de pessoas vinculadas por laços de afeto (real ou presumido) num contexto de conjugalidade ou parentalidade (RAMOS, 2016, p. 29).

A autora explica também que a família como organismo social, tem o seu fundamento na natureza e nas necessidades naturais da união sexual, na procriação, no amor mútuo, na assistência, na confiança e na cooperação, que são as razões de sua existência, a família tem notável influência da religião, do costume e da moral, nos quais encontra grande parte de sua regulamentação. $E$ antes de jurídico, a família é um fato sociológico (RAMOS, 2016, p. 29).

Pereira (2020, p. 24) aduz que tradicionalmente, a família era considerada em relação: ao princípio da autoridade; aos efeitos sucessórios e alimentares; às 
implicações fiscais e previdenciárias; ao patrimônio. Em senso estrito, a família se restringia ao grupo formado pelos pais e filhos.

Quanto ao poder dentro da família, compreende-se que:

\begin{abstract}
Aí se exercia a autoridade paterna e materna, participação na criação e educação, orientação para a vida profissional, disciplina do espírito, aquisição dos bons ou maus hábitos influentes na projeção social do indivíduo. Aí se praticava e desenvolvia em mais alto grau o princípio da solidariedade doméstica e cooperação recíproca (PEREIRA, 2020, p. 24).
\end{abstract}

Atualmente, a família possui uma nova visão:

\begin{abstract}
Nova estrutura jurídica se constrói em torno do conceito da família socioafetiva, a qual alguns autores identificam como "família sociológica", onde se identificam, sobretudo, os laços afetivos, solidariedade entre os membros que a compõem, família em que os pais assumem integralmente a educação e a proteção de uma criança, que independe de algum vínculo jurídico ou biológico entre eles (PEREIRA, 2020, p. 24).
\end{abstract}

Para Ramos (2016, p. 30), o direito de família nitidamente se destaca e separa dos restantes ramos do direito privado: a sua história, o fundamento racional e social dos seus institutos, a prevalência do ponto de vista ético nas suas normas, o reconhecimento de questões emocionais e de sobrevivência, bem como a sua grande ligação com o direito público.

\title{
2.2 HISTÓRICO
}

De acordo com Pereira (2020, p. 27), quem rastreia a família em investigação sociológica encontra várias referências a estágios primitivos em que mais atua a força da imaginação do que a comprovação fática; mais prevalece a generalização de ocorrências particulares do que a indução de fenômenos sociais e políticos de franca aceitabilidade.

Porém, o autor explica que um fato certo e comprovado, pelos registros históricos, pelos monumentos literários, pelos fragmentos jurídicos, é que a família ocidental viveu largo período sob a forma "patriarcal" (PEREIRA, 2020, p. 27).

Assim, antigamente havia uma visão muito mais patrimonial e "fria" do direito de família, conforme explica Clóvis Bevilaqua, citado por Venosa (2018, p. 9): 
Direito de Família é o complexo das normas, que regulam a celebração do casamento, sua validade e os efeitos, que dele resultam, as relações pessoais e econômicas da sociedade conjugal, a dissolução desta, as relações entre pais e filhos, o vínculo do parentesco e os institutos complementares da tutela e da curatela.

O autor demonstra uma forma de ver o direito de família muito mais patrimonialista e para a resolução de conflitos, alegando apenas que se tratava de um complexo de normas:

\begin{abstract}
Na definição do grande Beviláqua há que se acrescentar, hoje, as normas reguladoras das uniões sem casamento. É interessante observar que no passado qualquer referência jurídica à família tomava por base o casamento. Só mais recentemente a família foi observada pelos juristas sob prisma de instituição, abrangendo as uniões sem casamento e até mesmo as chamadas famílias monoparentais. A Constituição de 1988 ampliou, entre nós, o conceito de família, para reconhecer 'como entidade familiar a comunidade formada por qualquer dos pais e seus descendentes', bem como a união estável entre o homem e a mulher (art. 226) (BEVILACQUA apud VENOSA, 2018, p. 10)
\end{abstract}

A gênese da família encontrava-se na autoridade parental e na marital, ungidas à força suprema da crença religiosa, sendo, na concepção antiga, a sua formação mais uma associação religiosa que uma formação natural (MALUF; MALUF, 2016, p. 31).

Para Ramos (2016, p. 31), a família, no direito romano, que tanto influenciou a família ocidental, caracteriza-se por ser rigidamente patriarcal e por constituir um agrupamento que goza de relativa autonomia em relação ao Estado. O Estado Romano não interferia nas questões surgidas no seio da família.

O pater familias era o chefe absoluto, sacerdote incumbido de oficiar a veneração dos penates, deuses domésticos. Como chefe do grupo familiar, exercente do poder marital, tinha direitos absolutos sobre a mulher e os filhos, inclusive com direito de vida e morte sobre os últimos, decorrente do jus vitae necisque. O pater familias era titular do jus noxae dandi, consistente no abandono reparatório do filho em favor da vítima que houvesse sofrido prejuízo com a prática pelo filho de um ilícito privado. Podia também exercer o jus vendendi, que era a faculdade de alienar o filho, mediante mancipatio a outro pater familias. Subespécie do jus vitae necisque era o jus exponendi, faculdade do pater familias de abandonar o filho recém-nascido ao seu destino. Só o pater familias tinha patrimônio, exercendo a domenica potestas. A mulher era considerada inabilitada para os negócios da vida forense. Daí a capitis deminutio de que padecia, que repercutiu na família moderna (RAMOS, 2016, p. 31-32). 
Nesta esteira do patriarcalismo na família, Pereira (2020, p. 27) aduz que o pater atuava, ao mesmo tempo, como chefe político, sacerdote e juiz. Comandava, oficiava o culto dos deuses domésticos e distribuía justiça.

Salienta-se que, no Brasil, o direito de família sofreu grande influência do direito romano e do cristianismo, notadamente de concepções da igreja católica. (RAMOS, 2016, p. 32).

Atualmente não se pode mais ter essa visão pela evolução que até mesmo no direito constitucional, o direito de família foi elevado, tanto que o Estado, por meio da Constituição garante especial proteção.

A evolução histórica da família nos traz, assim, o afeto como centro da discussão jurídica (RAMOS, 2016, p. 34).

\subsection{LEGISLAÇÃO PERTINENTE}

Carlos Roberto Gonçalves (2020, p. 31) aduz que o Código Civil de 1916 e as leis posteriores, vigentes no século passado, regulavam a família constituída unicamente pelo casamento, de modelo patriarcal e hierarquizada, ao passo que $o$ moderno enfoque pelo qual é identificada tem indicado novos elementos que compõem as relações familiares, destacando-se os vínculos afetivos que norteiam a sua formação. Nessa linha, a família socioafetiva vem sendo priorizada pela doutrina e jurisprudência.

Assim, imperioso destacar a importância que o Código Civil de 2002 e a Constituição Federal de 1988 têm para que o direito de família se modernizasse.

\subsubsection{Código Civil}

O Código Civil de 2002 institui, em seu artigo 1.584, que a guarda poderá ser unilateral ou compartilhada. $O \S 1^{\circ}$ do mesmo artigo determina que a guarda unilateral é aquela atribuída a um só dos genitores ou a alguém que o substitua, e, por guarda compartilhada a responsabilização conjunta e o exercício de direitos e deveres do pai e da mãe que não vivam sob o mesmo teto, concernentes ao poder familiar dos filhos comuns (BRASIL, 2002). 
O Código de 2002 destina um título sobre o direito patrimonial da família. Através do artigo 1.511, demonstra a igualdade entre os cônjuges, materializando a paridade no exercício da sociedade conjugal, através dos direitos e deveres.

O Código Civil trouxe diversas modificações no direito de família, dentre elas, podem ser citados:

\begin{abstract}
O novo diploma amplia, ainda, o conceito de família, com a regulamentação da união estável como entidade familiar; revê os preceitos pertinentes à contestação, pelo marido, da legitimidade do filho nascido de sua mulher, ajustando-se à jurisprudência dominante; reafirma a igualdade entre os filhos em direitos e qualificações, como consignado na Constituição Federal; atenua o princípio da imutabilidade do regime de bens no casamento; limita o parentesco, na linha colateral, até o quarto grau, por ser este o limite estabelecido para o direito sucessório; introduz novo regime de bens, em substituição ao regime dotal, denominado regime de participação final nos aquestos; confere nova disciplina à matéria de invalidade do casamento, que corresponde melhor à natureza das coisas; introduz nova disciplina do instituto da adoção, compreendendo tanto a de crianças e adolescentes como a de maiores, exigindo procedimento judicial em ambos os casos; regula a dissolução da sociedade conjugal, revogando tacitamente as normas de caráter material da Lei do Divórcio, mantidas, porém, as procedimentais; disciplina a prestação de alimentos segundo nova visão, abandonando o rígido critério da mera garantia dos meios de subsistência; mantém a instituição do bem de família e procede a uma revisão nas normas concernentes à tutela e à curatela, acrescentando a hipótese de curatela do enfermo ou portador de deficiência física, dentre outras alterações (GONÇALVES, 2020, p. 34).
\end{abstract}

Quanto à guarda compartilhada, o Código Civil de 2002 institui, em seu artigo 1.584, que a guarda pode ser unilateral ou compartilhada. $\mathrm{O} \S 1^{\circ}$ do mesmo artigo determina que a guarda unilateral é aquela atribuída a um só dos genitores ou a alguém que o substitua, e, por guarda compartilhada a responsabilização conjunta e o exercício de direitos e deveres do pai e da mãe que não vivam sob o mesmo teto, concernentes ao poder familiar dos filhos comuns (BRASIL, 2002).

O $\S 3^{\circ}$ do artigo 1.584 define que na guarda compartilhada, a cidade considerada base de moradia dos filhos será aquela que melhor atender aos interesses dos filhos (BRASIL, 2002), sendo assim, observado o princípio do melhor interesse da criança e do adolescente explicitamente.

Conforme dispõem os parágrafos do artigo em tela, Carlos Alberto Dabus Maluf e Adriana Caldas do Rego Maluf (2016, s.p.) explicam: 
[...] informará o juiz o significado da guarda compartilhada (§ 10); estipulará a sua guarda compartilhada nos casos em que não houver consenso dos genitores (§ 20); estabelecerá as atribuições dos pais na guarda compartilhada (§ 30$)$; reduzirá as prerrogativas atribuídas ao detentor da guarda, inclusive quanto ao número de horas de convivência com o filho (§ 4o); e proferirá a redesignação do guardião em atenção ao melhor interesse da criança (§ 50$)$, quando necessário.

Desta forma, denota-se que quando não há consenso entre os pais, e atendendo ao princípio do melhor interesse da criança e do adolescente, a guarda estipulada será a compartilhada.

\subsubsection{Constituição Federal}

A Constituição Federal de 1988 possui capítulo próprio que trata da família, da criança, do adolescente e do idoso (Capítulo VII, do Título VIII - Da Ordem Social).

Para Ramos (2016, p. 35), o fortalecimento do direito de família, com a consagração dos princípios previstos na Constituição Federal, transformou o casamento e a família em geral em instrumento de felicidade e promoção da dignidade de cada um de seus membros, com fulcro no respeito e na realização pessoal destes.

Segundo Rolf Madaleno (2020, p. 39), interpretando-se o artigo 226 da Constituição Federal, pode-se dizer que a família é decorrente dos seguintes institutos:

- Casamento civil, sendo gratuita a sua celebração e tendo efeito civil o casamento religioso, nos termos da lei (art. $226, \S \S 1 .^{\circ}$ e $2 .^{\circ}$ ).

- União estável entre homem e mulher, devendo a lei facilitar a sua conversão em casamento (art. 226, § $3 .^{\circ}$ ). A união estável está regulamentada nos arts. 1.723 a 1.727 do $\mathrm{CC} / 2002$, sem prejuízo de outros dispositivos da atual codificação.

- Entidade monoparental, ou seja, a comunidade formada por qualquer dos pais e seus descendentes (art. 226, § 4..$^{\circ}$ ). Não há qualquer regulamentação específica dessa entidade no Código Civil ou em outra lei especial

O Carlos Roberto Gonçalves (2020, p. 32) complementa que a nova Carta abriu ainda outros horizontes ao instituto jurídico da família, dedicando especial atenção ao planejamento familiar e à assistência direta à família (art. 226, $\S \S 7^{\circ} \mathrm{e}$ $\left.8^{\circ}\right)$. 
De acordo com Ramos (2016) a Constituição Federal de 1988 trouxe inúmeras inovações na estrutura familiar. E, dentre elas, a família ganhou destaque, em virtude das profundas modificações que sofreu.

Conforme expõe:

\begin{abstract}
Enquanto a família presente no Código Civil Brasileiro de 1916 é fundada no casamento, havendo distinção quanto aos filhos, com característica essencialmente patrimonialista e patriarcal, a família contemporânea, fruto da evolução da sociedade e da própria legislação, agora regulada pelo Código Civil de 2002, interpretado à luz da Constituição Federal de 1988, é baseada no amor, na promoção da dignidade de seus membros, com o reconhecimento de outras formas ou modelos de entidades familiares além do casamento, como as uniões estáveis e aquelas formadas pela união de qualquer dos pais e sua prole (famílias monoparentais), reconhecendo direitos iguais a todos os filhos, sejam eles oriundos ou não do casamento, e igualdade entre o homem e a mulher (RAMOS, 2016, p. 34)
\end{abstract}

Com a Constituição Federal, que estabeleceu o princípio da igualdade, também se determinou que ambos os genitores passam a exercer de forma equilibrada o poder familiar sobre os filhos, cabendo àquele que se encontrar inconformado, procurar seus direitos junto à justiça (DIAS, 2010 p. 417).

\title{
3 DA GUARDA E DO PODER FAMILIAR
}

A guarda é atributo do poder familiar, e se refere à convivência propriamente dita, constituído do direito de viver com o filho menor ou incapaz na mesma habitação, com o correspondente dever de assumir a responsabilidade direta de velar pelos interesses do filho, a quem representa em juízo nas ações em que for parte, sendo a custódia uma decorrência da separação dos pais, tenham sido ou não casados (OTERO apud, MADALENO, 2020, p. 109).

Tratando da proteção da pessoa dos filhos, dispõe o art. 1.583 do CC, sobre as modalidades de guarda previstas na lei: unilateral ou compartilhada (MALUF; MALUF, 2020, p. 626). Assim, conceitua-se a guarda, a guarda compartilhada que é o foco do presente artigo, e o poder familiar. 


\title{
3.1 DA GUARDA
}

Conforme pode ser extraído da legislação em vigor, a guarda é um desdobramento do poder familiar e traduz um conjunto de obrigações e direitos em face da criança ou adolescente, de assistência material e moral. Historicamente, o direito de guarda não era regulamentado pela Codificação de 1916, que se limitava a identificá-lo como mero desdobramento do poder familiar (DELGADO; COLTRO, 2018, p. 53).

Em primeiro lugar, conforme destaca Grisard Filho (2010), o instituto da guarda é um direito, como o de reter o filho no lar, conservando-o junto a si, o de reger sua conduta, o de reclamar de quem ilegalmente o detenha, o de proibir-lhe companhias nefastas e de frequentar determinados lugares. A guarda é de natureza do poder familiar, não da sua essência, tanto que transferida a terceiro não implica a transferência deste. A criação e a educação dos filhos cabem aos pais, conforme os arts. 1634, I, do CC, 22 do ECA e 229 da Carta Magna.

Rolf Madaleno (2020, p. 109) aduz que é item condicional e inarredável de qualquer separação dos pais, o estabelecimento da guarda, compartilhada ou unilateral e os fatos irão indicar a melhor solução, cujo pré-requisito é igualmente relevante ao estabelecimento da custódia, e para o ajuste sobre o montante alimentar a ser pago pelo genitor predominantemente provedor.

Segundo Grisard Filho:

\begin{abstract}
O dever de educar abrange o de correição e disciplina, ainda que não haja previsão expressa na lei. $O$ dever de assistência compreende-se os aspectos morais que se confundem com o dever de educação e os aspectos materiais enquanto se referem à obrigação alimentar, segundo a condição e a fortuna dos pais. $O$ direito de guarda também compreende 0 de vigilância, pelo qual se efetiva o dever de dirigir a criação do menor no aspecto de sua formação moral. $\mathrm{O}$ dever de fiscalização decorre dos pais em vigiar a correspondência do menor, fixar-Ihes horários para estudos, trabalho e lazer, bem como zelar por sua saúde (GRISARD FILHO, 2010, p. 47).
\end{abstract}

É inerente aos filhos o dever de respeitar e obedecer aos seus pais, mas também prestar-lhes serviços compatíveis, seja através da participação no sustento da família como na execução de pequenas tarefas domésticas ou remuneradas, conquanto respeitem as restrições da legislação trabalhista e não tenha risco ao 
desenvolvimento psíquico, moral, educacional e físico do menor. Cabe ressaltar a importância da orientação dos pais na escolha do trabalho compatível com a idade e a condição do filho, visto que tal orientação faz parte da função de criar e educar os filhos, porém não ocorrendo o cumprimento da função, poderão os pais perder o poder familiar (VENOSA, 2018).

Por fim, Rolf Madaleno (2020, p. 109) explica que prevalece o princípio dos melhores interesses da criança ao considerar como critério importante para definição da guarda apurar a felicidade dos filhos, e não os de se voltar para os interesses particulares dos pais, ou para compensar algum desarranjo conjugal dos genitores e Ihes outorgar a guarda como um troféu entregue ao ascendente menos culpado pela separação.

\title{
3.1.1 Da Guarda Compartilhada
}

O fundamento da guarda compartilhada era na experiência brasileira a prática do poder familiar, porque somente unidos pelo casamento ou pela estável convivência, em relação familiar de total harmonia, seria viável a adoção da guarda compartilhada, pois nesse caso estariam os pais realmente compartilhando a custódia dos filhos, conciliando com a sua estável relação e fluido diálogo os interesses dos filhos comuns, sem alternar o tempo de estadia com a prole (MADALENO, 2020, p. 118).

Quanto ao surgimento e descrição da guarda compartilhada, Pereira (2020, p. 547) leciona:

\begin{abstract}
A Guarda Compartilhada foi instituída pela Lei $n^{\circ} 11.698$, de 13 de junho de 2008. Mantida a residência fixa de comum acordo com qualquer deles ou com terceiros, nesta modalidade de guarda os filhos permanecem assistidos por ambos os pais, dividindo responsabilidades, sem a necessidade de fixação prévia e rigorosa dos períodos de convivência, cabendo-lhes as principais decisões relativas à educação, instrução, religiosidade, saúde, lazer etc.
\end{abstract}

Segundo Rolf Madaleno (2020, p. 109) o artigo 1.583 do Código Civil ordena que na guarda compartilhada o tempo de convívio com os filhos seja dividido de forma equilibrada com a mãe e com o pai, sempre tendo em vista as condições fáticas e os interesses dos filhos, e sempre sob esta visão exclusiva deve ser 
judicialmente examinada a questão relativa à guarda compartilhada, que nem sempre deverá constituir-se na melhor solução voltada para os interesses da criança e do adolescente.

Cumpre notar que a guarda compartilhada não se confunde com a guarda alternada. Na guarda compartilhada o menor tem um domicílio único, e na guarda alternada há duplicidade de domicílios - o do pai e o da mãe (MONTEIRO apud, MALUF; MALUF; 2020, p. 626).

Conforme explica Pereira (2020, p. 547), ressalta-se que a guarda compartilhada não exclui a fixação do regime de convivência (Enunciado $n^{\circ}$ 605) e não implica ausência de pagamento de pensão alimentícia (Enunciado $n^{\circ} 607$ ).

A guarda compartilhada possui suas polêmicas, conforme explicam Delgado e Coltro (2018, p. 59):

\begin{abstract}
Primeira delas é se existe a necessidade de acordo entre os cônjuges. Presente questão não é pacifica na doutrina, pois aponta Rolf Madaleno que teríamos mais complicações de convivência quando essa for obrigatória. Não obstante, as recentes reformas do Código Civil, acordes com o Superior Tribunal de Justiça, indicam que não há necessidade de consenso, pois a guarda compartilhada configura uma nítida ferramenta de aproximação. Atinente à presente temática, Flávio Tartuce pondera que o caminho ideal seria a implementação dessa modalidade de guarda, com a utilização da mediação. Em continuidade, outro ponto polêmico são os alimentos. Deve ser registrado que, nessa modalidade de guarda, o que se compartilha é a convivência e não as despesas. Muitos pais não compreendem essa regra, pois muitas vezes há o interesse de implementação da guarda compartilhada para se exonerar do pagamento dos alimentos. Por fim, porém não menos importante, não pode existir na guarda compartilhada a regulamentação de direito de visita.
\end{abstract}

Pelo atual paradigma da igualdade dos direitos dos pais, o modelo de custódia compartilhada da prole (alternância de tempo) estaria resguardando o princípio dos melhores interesses da criança e do adolescente, e isto justificaria a supressão do argumento da tenra idade pela simetria das funções parentais (MADALENO, 2020, p. 118).

\title{
3.2 DO PODER FAMILIAR
}

No ordenamento vigente não há uma definição pura de poder familiar, e sim regulamentação de situações específicas como competência, titularidade, exercício, 
suspensão e extinção. Situações estas que estão todas elencadas no Código Civil de 2002, em seu Livro IV, que trata a respeito do direito de família, nos artigos 1.630 à 1.638 (COMEL, 2003, p. 64).

Sendo necessário, desta forma, o auxílio dos doutrinadores a fim de encontrar definições que se enquadram para a sociedade atual e maior satisfação do infante.

O pátrio poder, hoje denominado poder familiar, teve sua origem na Roma Antiga, onde a lei autorizava o pai a vender ou até mesmo tirar a vida de seu filho, era o poder/dever que o pai tinha sobre a pessoa dos filhos, no qual ele detinha o posto de chefe da família, logo, senhor das decisões, sendo que não se falava no poder do pai e da mãe, mas somente no poder do homem (VENOSA, 2018).

Segundo Lôbo (2018), este entendimento perdurou por toda a história de Roma, passando pelos períodos de República e Império, vindo a conhecer seu ocaso apenas com o advento e popularização do Cristianismo:

Com o cristianismo e a valorização familiar de ambos os cônjuges, perdendo poder a figura paterna no seio familiar. Este movimento acabou por tornar responsabilidade paterna o desenvolvimento educacional, social e religioso dos filhos por parte dos pais, fortalecendo a instituição dos que detinham o poder sobre outro (LÔBO, 2018, s.p.).

No entanto, o Código Civil de 1916 recebeu por completo os preceitos do poder pátrio legados pelo direito romano, garantindo o pátrio poder exclusivamente para o pai, sendo a mãe submissa, pois nada podia decidir quanto à educação de seus filhos. A mulher, neste sentido, era vista como alguém incapaz de praticar qualquer ato da vida civil e, portanto, incapaz de decidir pelo futuro de seus filhos e incapaz de deter sobre eles o mesmo poder que os pais detinham (GRISARDI FILHO, 2010).

\footnotetext{
A conotação machista do vocábulo pátrio poder é flagrante, pois só menciona o poder do pai com relação aos filhos. Como se trata de um termo que guarda resquícios de uma sociedade patriarcal, o movimento feminista reagiu, daí o novo termo: poder familiar (DIAS, 2006, p. 343).
}

O poder familiar se tornou mais um dever do que propriamente um poder, pois está mais em favor dos direitos e necessidades dos filhos do que o de seus genitores, sendo assim, resta dizer que os pais devem juntos, desempenhar as obrigações relativas à entidade familiar, como, o dever de sustento, guarda e 
educação dos filhos menores, conforme preceitua o artigo 22 do Estatuto da Criança e do Adolescente de 1990, que assim o descreve: "Aos pais incumbe o dever de sustento, guarda e educação dos filhos menores, cabendo-lhe ainda, no interesse destes, a obrigação de cumprir e fazer cumprir as determinações judiciais" (BRASIL, 1990).

O poder familiar, sendo menos um poder e mais um dever, converteu-se em um múnus, e talvez se devesse falar em função familiar ou em dever familiar. A modificação não passou de efeito de linguagem, tendo em vista que a ideia contida na nova nomenclatura é, ainda, apegada ao contexto familiar da sociedade do século passado (DIAS, 2010, p. 417).

Com o advento de novas legislações o termo poder pátrio foi aos poucos sendo substituído para termos que melhor acomodassem a realidade nele contida. Uma das primeiras alterações foi renomear para "poder familiar", fazendo assim alusão a ambas as figuras parentais (VENOSA, 2018).

Essa mudança gerou mal estar na doutrina, que via o termo como abrangendo todo o arcabouço familiar, lançando responsabilidades a outros entes familiares que não os pais. Acabou por se adotar o termo "autoridade parental", ainda que a percepção da palavra autoridade não seja a mesma de tempos anteriores (VENOSA, 2018).

Segundo Rolf Madaleno (2020, p. 251), o poder familiar tem como foco constitucional os melhores interesses da criança e do adolescente, e não mais a supremacia da vontade do pai, chefe da sociedade familiar.

Tal mudança de paradigma também não significa que as crianças não mais enxerguem seus pais como autoridades a serem respeitadas, mas compreendem que sua criação, educação e bem estar é responsabilidade de seus genitores. $O$ termo "responsabilidade parental" é o que melhor redefine a acepção do instituto nos dias de hoje (VENOSA, 2018).

Sílvio de Salvo Venosa (2018) faz uma ressalva quanto ao termo poder familiar e sua vinculação: Vale ressaltar que o termo 'poder familiar' não está condicionado ao
casamento ou a nenhum contrato jurídico de qualquer forma. Ele se estende
naturalmente as uniões estáveis, conforme o artigo 1.361 do Código Civil de
2002. Ele estabelece que o poder familiar compete aos pais, ou em caso de
impedimento ou falta de um, o outro poderá exercer o poder com

Acad. Dir. (ISSNe: Em processo de criação)

v. 3, p. $1-21,2021$ 
exclusividade. Ainda no mesmo artigo é citado que em havendo divergências a respeito do uso do poder familiar, é assegurado a ambas as partes o direito de recorrer a autoridade judicial para solucionar o desacordo (VENOSA, 2018, s.p.).

O Poder Familiar é um instituto constituído de diversas obrigações; é irrenunciável, imprescritível, inalienável e incompatível (VENOSA, 2018).

Segundo Rolf Madaleno (2020, p. 251):

\begin{abstract}
Existe um conjunto de direitos e de deveres que interage no propósito de atribuir aos pais uma função de bem se desempenharem no exercício do seu poder familiar, valendo-se da sintonia de seus deveres e dos seus direitos como pais, na tarefa de bem administrarem a pessoa e os bens de sua prole, com vistas a alcançarem a integral e estável formação dos seus filhos.
\end{abstract}

A fim de garantir que dessa forma seja o Estado mantêm vigilância sobre o poder familiar, assegurando que as crianças frequentem a escola, não sofram maus tratos e sejam criadas com todas as necessidades que o Estatuto da Criança e Adolescente assim sugere (VENOSA, 2018).

Porém, conforme muito bem aponta a doutrina, não obstante o poder familiar seja indelegável, irrenunciável e imprescritível, portanto, personalíssimo, pode ser dividido didaticamente, conforme Delgado e Coltro (2018, p. 48) em:

a) tutela de criação: tem forte relação com o ECA, em especial os institutos da convivência familiar e comunitária (art. 1634, I e II do CC);

b) tutela de representação: tem forte relação com os atos da vida civil, sem o que os mesmos podem ser nulos ou anulados (art. 1634, III até VII do $\mathrm{CC})$;

c) tutela de proteção: tem forte relação com exercício regular e desenvolvimento integral (art. 1634, VIII e IX do CC).

Esse último desdobramento é um dos mais abrangentes, pois pode ser objeto de questionamento e embates em situações como: regulamentação e retenção indevida de guarda, sequestro e rapto de incapaz, abandono ou maus-tratos por instituições de ensino.

É dever absoluto dos pais, por exemplo, prover aos filhos os meios materiais para sua sobrevivência, preparando-Ihes para a vida adulta e assegurando a eles todos os direitos da pessoa humana. Compromisso dos pais aos filhos o de promover o desenvolvimento físico, mental, moral, espiritual e social, condições de liberdade e dignidade (VENOSA, 2018). 
A boa relação de pai e/ou mãe com os filhos é o que importa. Em casos de separação, isso mais e mais se evidencia (DELGADO; COLTRO, p. 94). Por essa razão, Grzybowski (2007, p. 28) conclui que receber "[...] cuidados maternos não é garantia de desenvolvimento saudável, assim como a ausência de um dos progenitores nem sempre é danosa".

Muito embora, o Estatuto exponha clareza quanto a promoção dos deveres inerentes aos pais, bem como os direitos, a presente norma jurídica não dispõe sobre a forma que os filhos devem ser criados nem mesmo como deve ser a atuação dos afazeres parentais. Por sua vez, isto decorre da convivência familiar e da maneira em que as decisões familiares devem ser tomadas, na medida em que a vida íntima da família se desenvolve naturalmente e sua estrutura deve ser norteada pela prudência (VENOSA, 2018).

\section{DO PRINCÍPIO DO MELHOR INTERESSE SENDO GARANTIDO PELO EXERCÍCIO DA GUARDA COMPARTILHADA}

Delgado e Coltro (2018, p. 165) observam que no sistema jurídico anterior ao advento da Lei $n^{\circ} 11.698 / 08$ e da Lei $n^{\circ} 13.058 / 14$, era controvertida a admissibilidade da guarda compartilhada na jurisprudência brasileira.

Segundo os autores, conforme um levantamento estatístico feito pelo IBGE, referente ao registro civil do ano de 2002, a maior parte das dissoluções de sociedade conjugal foi consensual (79\% das separações formais e $70 \%$ dos divórcios, a guarda dos filhos ficou na maior parte dos casos com a mãe, sendo que os pais ficaram com a guarda em apenas $4,8 \%$ das separações e $5,8 \%$ dos divórcios (DELGADO; COLTRO, 2018).

Quanto ao princípio do melhor interesse, este foi albergado pela Convenção das Nações Unidas sobre Direitos da Criança de 1990 e restou ratificado integralmente pelo Brasil no Decreto $n^{\circ}$ 99.710/1990. Segundo Amin (2015, p. 70), "trata-se de um princípio orientador tanto para o legislador como para o aplicador" que, portanto, estabelece como prioridade as necessidades da criança e do adolescente como norte para a aplicação e elaboração das leis. Para salvaguardar este princípio, Ishida (2014, p. 2) destaca a necessidade da "reunião de profissionais do Direito especializados em matéria de Direito da Criança e do Adolescente e de 
outros técnicos voltados ao tema". Por decorrer de tratado internacional homologado pelo Brasil, este princípio tem caráter supralegal, conforme interpretação dada pelo Supremo Tribunal Federal ao artigo $5^{\circ} \S 2^{\circ}$ da Constituição Federal (BRASÍLIA, 2008).

Em função disso, Rossato, Lépore E Cunha (2012, p. 84) referem que esse princípio "é o modo como o direito da criança e do adolescente deve ser concretizado, situando-se em um segundo grau e estabelecendo a estrutura de aplicação de outras normas (princípios e regras)". Ao seu turno, o princípio da proteção integral está inserido no artigo 227 da Constituição Federal que dispõe sobre os direitos fundamentais da criança, do adolescente e do jovem. Embora este dispositivo não esteja inserido Título II da Carta Magna, ele compõe os direitos e garantidas constitucionais.

Quanto ao ponto, Mendes e Branco (2012, p. 41) destacam tratar-se de um artigo inserido na parte dogmática da Constituição, onde "o constituinte proclama direitos fundamentais, declarando e instituindo direitos e garantias individuais, como também direitos econômicos, sociais e culturais". Dimoulis e Martins (2014, p. 25) acrescentam que "a Constituição Federal de 1988 não se caracteriza pela sistematicidade com relação à garantia dos direitos fundamentais. Referências a tais direitos encontram-se em diversas partes do texto constitucional”.

A guarda conjunta ou compartilhada, trata-se de uma divisão da guarda, em condições igualitárias, ou parcialmente igualitária de tempo compartilhado dos pais para com à criança e adolescente após a dissolução da sociedade conjugal. Reflete ainda em uma igualdade no que se refere à tomada de posições que influenciará na construção da personalidade do filho (BEZERRA NETO; CAIANA; LEANDRO; SANTOS, 2019)

A guarda compartilhada surgiu com o intuito de reequilibrar os papeis parentais, uma vez que a sociedade encontra-se insatisfeita com a forma a qual está sendo deferida a guarda nos tribunais. Com a finalidade de eliminar com essa desigualdade que rege em nossos tribunais, vários doutrinadores iniciaram a reivindicar que na lide da guarda de menores o magistrado primeiramente tentasse apresentar para os pais a possibilidade do modelo da guarda compartilhada e os benefícios que traria para o menor, e, só depois dessa tentativa se não houvesse 
existo é que se buscaria o modelo da guarda única (BEZERRA NETO; CAIANA; LEANDRO; SANTOS, 2019).

A dissolução dos casais desde o nascimento da Lei do Divórcio tornou-se comum nas varas de família. Como assim era a decisão considerada pela maioria dos juízes a guarda única continuava à mãe, como também evoluía a ideia de que o pai permanecia com a guarda, pois a criança não tem responsabilidade de sua família se dissipar-se e daí surge a ideia da perenidade da presença dos pais na vida de seus filhos. A guarda é um dever recíproco de ambos os cônjuges, conceito este expressamente velado no art. 1566, inc. IV, do CC, portanto, o direito de companhia e guarda é tanto da mãe quanto do pai, mesmo que separados. A guarda dos filhos não estabelece, por si só, o exercício do poder familiar, sendo apenas uma de suas características (CARVALHO, 2016).

Desta forma a criança obtém a oportunidade de gozar do amor, afeto, carinho e educação dos pais, sendo este a pretensão do princípio do melhor interesse da criança e do adolescente. Devem ser preservadas o equilíbrio emocional, o estado de espírito, a proximidade familiar entre outras importâncias do menor assim como a paridade entre homens e mulheres (CARVALHO, 2016).

Com referência a este ponto de partida deste ordenamento tendem alguns magistrados a não mais priorizar a mães para a guarda exclusiva do filho, da forma fixada no artigo 10 , parágrafo $1^{\circ}$, da Lei n. 6.515/1977, a Lei do Divórcio, assim como do artigo 16 do Decreto Lei n. 3.200/1944. Sendo assim, a guarda sendo destinada à mãe, não ocorre ofensa ao poder familiar, pois o direito à guarda é da natureza e não da essência, do poder familiar, logo pode ser confiado a outrem.

Ter para si a guarda não é apenas um direito dos pais como também é um poder-dever em relação aos filhos, dever este de criar e guardar. O poder atribuído aos pais de zelar pela guarda dos filhos implica em tomar decisões quais sejam permissões ou proibições de onde ou com quem o filho pode ou deve conviver, por isso explica-se a necessidade de observação a quem é confiado à guarda dos filhos, pois está em jogo a vida material e moral dos filhos (BRASIL, 2002).

Sendo confiada a guarda dos filhos à pessoa que possa prejudicar a vida dos mesmos, podem os pais serem punidos à luz do art. 245 do Código Penal, bem como são também responsáveis pela reparação civil objetiva, com fulcro no artigo 932 do Código Civil. Ressalta-se que os pais são civilmente responsáveis pelos atos 
dos filhos menores, que estão sobre sua companhia e guarda, logo, o direito a guarda abrange também o da vigilância, que torna concreto o poder de dirigir a formação moral do menor, porém devendo sempre ser observado a dignidade e proteção integral dos interesses do menor (BRASIL, 2002).

Desta forma, os anseios da criança e do adolescente são garantidos através do princípio do melhor interesse, que busca que o juiz, sempre que possível, recomende o regime de guarda compartilhada, a fim de que se evitem os prejuízos decorrentes dos conflitos entre os pais quanto à criação do filho. Visa, sobretudo, que a criança e o adolescente possuam um desenvolvimento em ambiente sadio.

\section{CONSIDERAÇÕES FINAIS}

A partir da presente pesquisa, pode-se concluir atualmente, o instituto da guarda compartilhada é amplamente procurado pelo fato da mulher ter se inserido no mercado do trabalho, bem como se está consolidando a igualdade entre o homem e a mulher, fazendo com que o ordenamento jurídico brasileiro busque atender aos anseios da criança compartilhando a guarda entre os pais.

Os anseios da criança e do adolescente são garantidos através do princípio do melhor interesse, que busca que o juiz, sempre que possível, recomende esse regime de guarda, a fim de que se evitem os prejuízos decorrentes dos conflitos entre os pais quanto à criação do filho. Visa, sobretudo, que a criança e o adolescente possuam um desenvolvimento em ambiente sadio.

A guarda compartilhada, além de proporcionar o melhor interesse ao menor, proporciona aos pais a conservação do vínculo de afetividade, mesmo após o divórcio, e desta forma não há a interrupção dos laços fraternais, assim como o tratamento igualitário entre os membros familiares permanece. A criança continuará vendo ambos os pais de forma que manterá a afetividade, o que muitas vezes não ocorre com a guarda unilateral.

Desta forma, o presente artigo demonstra sua importância pelo fato de ser o melhor instituto para o bem estar da criança e do adolescente, e para que este cresça com a participação, tanto do pai, quanto da mãe, sem uma lacuna emocional. 


\section{REFERÊNCIAS}

BEVILÁQUA, Clóvis. Comentários ao código civil dos Estados Unidos do Brasil, edição histórica. Rio de Janeiro: Rio, 1975, v. I.

BRANCO, Paulo Gustavo Gonet; MENDES, Gilmar Ferreira. Curso de direito constitucional. 7. ed. rev. e atual. São Paulo: Saraiva, 2012.

BRASIL. Constituição da República Federativa do Brasil, promulgada em 05 de outubro de 1988. Disponível em: <http://www.planalto.gov.br>. Acesso em: 10.3. 2020.

BRASIL. Código Civil. Lei n. 10.406. 10 de janeiro de 2002. Disponível em: <http://www.planalto.gov.br/ccivil_03/Leis/2002/L10406compilada.htm>. Acesso em: 10.3. 2020.

BRASIL. Decreto n 99.710/1990 de 21 de novembro de 1990.

CARVALHO, Letícia de Fátima Faria de. A nova perspectiva do instituto da guarda compartilhada. Niterói: Universidade Federal Fluminense, 2016.

COMEL, Denise Damo. Do poder familiar. São Paulo: Revista dos Tribunais, 2003.

DIAS, Maria Berenice. Manual de direito das famílias. 4. ed. Porto Alegre: Livraria do Advogado, 2006

DELGADO, Mario; COLTRO, Antônio Carlos Mahias. Guarda compartilhada. 3.ed. Rio de Janeiro: Forense: 2018.

DIMOULIS, Dimitri; MARTINS, Leonardo. Teoria geral dos direitos fundamentais. 5. ed. São Paulo: Atlas, 2014.

GRISARD FILHO, Waldyr. Guarda compartilhada. 7. ed. São Paulo: Editora Revista dos Tribunais, 2010.

GRZYBOWSKI, Luciana Suárez. Parentalidade em tempo de mudanças: desvelando o envolvimento parental após o fim do casamento. 2007. $103 \mathrm{f}$. Tese (Doutorado em Psicologia) - Pontifícia Universidade Católica do Rio Grande do Sul, Porto Alegre, 2007.

ISHIDA, Valter Kenji. Estatuto da criança e do adolescente: doutrina e jurisprudência. 15. ed. São Paulo: Atlas, 2014.

LOBO, Paulo. Direito civil: famílias. 8.ed. São Paulo: Editora: Saraiva, 2018.

MADALENO, Rolf. Curso de direito de família. 5. ed. Rio de Janeiro: Forense, 2013. 
MADALENO, Rolf. Manual de direito de família. 3. ed. Rio de Janeiro: Forense, 2020.

MALUF, Carlos Alberto Dabus; MALUF, Adriana Caldas do Rego Freitas Dabus. Curso de direito de família. 1. ed. São Paulo: Saraiva Educação, 2016.

MONTEIRO, Washington de Barros; SILVA, Regina Beatriz Tavares da. Curso de direito civil, São Paulo: Saraiva Educação, 2012.

MALUF, Carlos Alberto Dabus; MALUF, Adriana Caldas do Rego Freitas Dabus. Curso de direito de família. 1. ed. São Paulo: Saraiva Educação, 2016.

BEZERRA NETO, F. C; CAIANA, C. R. A; LEANDRO, R. J. L.; SANTOS, V. E. S. Guarda Compartilhada: Sob a Ótica do Princípio do melhor interesse da Criança e do Adolescente após a Lei N 11.698/2008. Rev.Bras.de Direito e Gestão Pública (Pombal, PB),7(01),53-60, jan./mar., 2019.

PEREIRA, Caio Mário da Silva. Instituições de direito civil. 28. ed. Rio de Janeiro: Forense, 2020, v. 5.

RAMOS, Patricia Pimentel de Oliveira Chambers. Poder familiar e a guarda compartilhada: novos paradigmas do direito de família. 2. ed. São Paulo: Editora Saraiva, 2016.

ROSSATO, Luciano Alves; LEPORE, Paulo Eduardo; CUNHA, Rogério Sanches. Estatuto da criança e do adolescente. 3. ed. São Paulo: Revista dos Tribunais, 2012.

VENOSA, Sílvio de Salvo. Direito civil: família. 18. ed. Rio de Janeiro: Atlas, 2018. v. 5

Artigo recebido em: 07/09/2020

Artigo aceito em: 22/10/2020

Artigo publicado em: 18/01/2021 